\title{
Prognostic role of alpha-fetoprotein in patients with hepatocellular carcinoma treated with repeat transarterial chemoembolisation
}

Gauri Mishra', Anouk Dev ${ }^{1}$, Eldho Paul ${ }^{2}$, Wa Cheung ${ }^{3}$, Jim Koukounaras ${ }^{3}$, Ashu Jhamb ${ }^{4}$, Ben Marginson ${ }^{4}$,

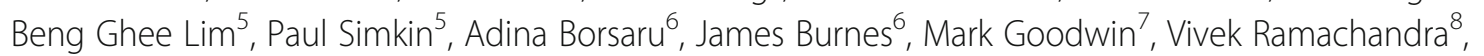
Manfred Spanger ${ }^{8}$, John Lubel ${ }^{9}$, Paul Gow ${ }^{10}$, Siddharth Sood ${ }^{11}$, Alexander Thompson ${ }^{12}$, Marno Ryan ${ }^{12}$, Amanda Nicoll ${ }^{13}$, Sally Bell ${ }^{1}$, Ammar Majeed ${ }^{9}$, William Kemp ${ }^{9}$, Stuart K. Roberts ${ }^{9 *}$ and The Melbourne Liver Group

\begin{abstract}
Background: Repeat transarterial chemoembolisation (rTACE) is often required for hepatocellular carcinoma (HCC) to achieve disease control, however, current practice guidelines regarding treatment allocation vary significantly. This study aims to identify key factors associated with patient survival following rTACE to facilitate treatment allocation and prognostic discussion.
\end{abstract}

Method: Patients with HCC undergoing rTACE at six Australian tertiary centers from 2009 to 2014 were included. Variables encompassing clinical, tumour, treatment type and response factors were analysed against the primary outcome of overall survival. Univariate analysis and multivariate Cox regression modelling were used to identify factors pre- and post-TACE therapy significantly associated with survival.

Results: Total of 292 consecutive patients underwent rTACE with mainly Child Pugh A cirrhosis (61\%) and BCLC stage A (57\%) disease. Median overall survival (OS) was 30 months (IQR 15.2-50.2) from initial TACE. On multivariate analysis greater tumour number $(p=0.02)$, higher serum bilirubin $(p=0.007)$ post initial TACE, and hepatic decompensation ( $p=0.001$ ) post second TACE were associated with reduced survival. Patients with serum AFP $\geq$ $200 \mathrm{ng} / \mathrm{ml}$ following initial TACE had lower survival $(p=0.001)$, compared to patients with serum AFP level that remained $<200 \mathrm{ng} / \mathrm{ml}$ post-initial TACE, with an overall survival of 19.4 months versus 34.7 months $(p=0.0001)$ respectively.

Conclusion: Serum AFP level following initial treatment in patients undergoing repeat TACE for HCC is a simple and useful clinical prognostic marker. Moreover, it has the potential to facilitate appropriate patient selection for rTACE particularly when used in conjunction with baseline tumour burden and severity of hepatic dysfunction post-initial TACE.

Keywords: Hepatocellular carcinoma, Repeat transarterial chemoembolisation, Prognosis, Alpha-fetoprotein

\footnotetext{
* Correspondence: S.Roberts@alfred.org.au

${ }^{9}$ Department of Gastroenterology, The Alfred Hospital, 55 Commercial Rd,

Melbourne 3004, Australia

Full list of author information is available at the end of the article
}

\section{$\triangle B M C$}

(c) The Author(s). 2020 Open Access This article is licensed under a Creative Commons Attribution 4.0 International License, which permits use, sharing, adaptation, distribution and reproduction in any medium or format, as long as you give appropriate credit to the original author(s) and the source, provide a link to the Creative Commons licence, and indicate if changes were made. The images or other third party material in this article are included in the article's Creative Commons licence, unless indicated otherwise in a credit line to the material. If material is not included in the article's Creative Commons licence and your intended use is not permitted by statutory regulation or exceeds the permitted use, you will need to obtain permission directly from the copyright holder. To view a copy of this licence, visit http://creativecommons.org/licenses/by/4.0/ The Creative Commons Public Domain Dedication waiver (http://creativecommons.org/publicdomain/zero/1.0/) applies to the data made available in this article, unless otherwise stated in a credit line to the data. 


\section{Background}

The majority of patients with unresectable HCC (uHCC) will undergo repeat transarterial chemoembolisation (TACE) therapy to optimize treatment response, however a significant proportion are at risk for an adverse outcome after repeat cycles due to either tumour progression or decline in hepatic reserve [1-4]. Whilst most international guidelines provide inclusion criteria for initial TACE, clinical criteria for eligibility for repeat TACE and factors predictive of poor outcomes are inadequately defined $[5,6]$. In this context, several scoring systems have been developed to facilitate guidance in this area such as ART (Assessment for Retreatment with TACE) [7, 8] and ABCR (Alpha-fetoprotein, BCLC stage, ChildPugh class, and radiological response) [9] score. However, their clinical utility has been limited in part due to their complexity and/or lack of applicability to the real world setting where on demand TACE is commonly employed and radiological response assessment has become more refined [10-13].

Therefore, further studies are required to identify key simple prognostic factors associated with overall survival (OS) following repeat TACE so as to improve patient selection and safety via the avoidance of unnecessary repeat procedures and unwanted side effects [6, 14]. Such prognostic data will facilitate clinician decision making and potentially improve patient survival as patients undergo timely stage migration to the next treatment option such as systemic therapy $[15,16]$.

In this study we analysed the prognostic factors associated with overall survival in patients undergoing repeat TACE and in particular the impact of the tumour marker alpha-fetoprotein (AFP). AFP is an established prognostic marker of both poorer $\mathrm{HCC}$ phenotype and more aggressive tumour biology [17-22]. While the optimum cut off value varies significantly in published literature on patients with HCC treated with TACE, it has been suggested that higher pre-treatment AFP is associated with earlier recurrence and poorer overall survival [23-25].

\section{Methods}

\section{Study population}

We retrospectively identified patients with $\mathrm{HCC}$ who had undergone TACE therapy from six tertiary centers in Melbourne, Australia between January 2009 and December 2014 using established HCC databases at each hospital and review of electronic medical records. All patients had the diagnosis of HCC confirmed on biopsy or established radiological criteria [26] and were deemed suitable for TACE after review by the multi-disciplinary team at the relevant hospital. Patients were included if they were classified as BCLC stage A, B, or C with relatively well preserved European Co-operative Oncology
Group (ECOG) performance status of 0-2. Subjects who had undergone at least two cycles of TACE were included, with the exception of those who were administered TACE as a bridge to liver transplantation.

Pre- and post-TACE clinical, radiological and laboratory characteristics were recorded, including presence of cirrhosis based on biochemical and radiological criteria as previously described $[16,27]$. Adverse events within 4 weeks of therapy were also recorded including hepatic decompensation as defined by the development of ascites, hepatic encephalopathy, hepatorenal syndrome or upper GI bleeding $[28,29]$. Following approval of a lowrisk application to the respective Institutional Ethics Committees, data regarding patient and tumour characteristics were collected for analysis, including clinical and radiological response, as defined by the mRECIST criteria [30, 31]. All patient data were de-identified prior to collation and statistical analysis.

\section{Primary outcome}

Overall survival was calculated from the date of first TACE treatment to either date of death or last clinical follow-up, with censoring at 31st January 2019. The date of death was obtained from either the patient hospital records and MDT databases at each hospital or if missing from the Victorian Death and/or Cancer Registry.

\section{Statistical analysis}

Continuous data were summarised using mean (standard deviation) or median (interquartile range) depending on the underlying distribution of the data. Categorical data were summarised using frequency tables, presenting the subject counts and percentages. Comparisons between groups (AFP $<200$ versus $\geq 200 \mathrm{ng} / \mathrm{ml}$ ) were made using the Student's t-test for normally distributed continuous variables, Wilcoxon rank-sum test for non-normally distributed continuous variables and chi-square or Fisher's exact test as appropriate for categorical variables.

The Kaplan-Meier product-limit method was used to plot survival as a function of time after treatment and to determine the median survival times. Comparisons between survival curves were made using the log-rank test. Univariate and multivariate analyses were performed via Cox proportional hazards regression to assess the effects of baseline clinical, liver disease, and tumour variables (pre-TACE 2) as well as tumour response variables (between TACE-1 and TACE-2) on overall survival.

Multivariate models were developed using a stepwise selection procedure and a backward elimination procedure before undergoing assessment for clinical and biological plausibility. Results from the Cox regression models were reported as hazard ratios (HR) and the corresponding 95\% confidence intervals (95\% CI). All reported $P$-values were two-sided with a $P<0.05$ 
indicating statistical significance. Analyses were performed with the SAS software version 9.4 (SAS Institute, Cary, NC, USA).

\section{Results}

\section{Patient characteristics}

A total of 431 patients received TACE for HCC from 2009 to 2014 inclusive, of these 292 received at least two TACE treatments and were included in this study (Table 1). This cohort comprised mainly of BCLC stage A (57\%) and B (39\%) disease (Table 1). The majority of patients were male $(87 \%)$, of Caucasian background (78\%) and had predominantly alcohol $(42 \%)$ or $\mathrm{HCV}$ (41\%) related chronic liver disease. At baseline most had well compensated Child Pugh A (61\%) cirrhosis with a smaller proportion having Child Pugh B disease (30\%). Most patients had conventional TACE (cTACE) (79\%) with the remainder receiving drug eluting beads TACE (DEB-TACE) (19\%) or bland embolisation (TAE) (1\%). Incomplete radiological response of the target lesion following initial TACE was common, as defined by mRECIST with majority having partial (43\%), stable (9\%) or progressive $(8 \%)$ disease. Repeat TACE was provided on demand in all patients at a median interval of 2.5 months (IQR 1.4-7.7) following initial TACE, with a few individuals undergoing $>6$ cycles. The most common complication of TACE observed was post-TACE syndrome (13\%) with liver decompensation occurring in $1 \%$ of patients.

Serum AFP data was available in 260 (89\%) patients prior to initial TACE, with the median baseline AFP level being $19 \mathrm{ng} / \mathrm{ml}$ (IQR 5-174.5). Of these patients, $135(52 \%)$ had levels below $20 \mathrm{ng} / \mathrm{ml}, 60$ patients $(23 \%)$ had AFP $\geq 200$ and 45 (17\%) were $\geq 400 \mathrm{ng} / \mathrm{ml}$ prior to initial TACE. Following initial TACE, 110 patients (42\%) had AFP of $<20 \mathrm{ng} / \mathrm{ml}$, while $30(12 \%)$ and $23(9 \%)$ had AFP $\geq 200 \mathrm{ng} / \mathrm{ml}$ and $\geq 400 \mathrm{ng} / \mathrm{ml}$ respectively. In total, 177 (61\%) of the overall cohort had AFP data available prior to both their first and second TACE for comparative analysis. Of these 30 patients (17\%) had an AFP $\geq$ $200 \mathrm{ng} / \mathrm{ml}$ following initial TACE therapy and 147 (83\%) had an AFP $<200 \mathrm{ng} / \mathrm{ml}$.

\section{Overall survival}

During a median follow-up of 28 months (IQR 14.845.4) after the initial TACE, there were 82 (28\%) patients who died. The median overall survival from time of first TACE therapy was 30 months (IQR 15.2-50.2) (Fig. 1).

\section{Predictors of overall survival Univariate analysis}

Univariate analysis compared all variables associated with OS encompassing hepatic synthetic function, tumour-related factors both pre- and post-initial TACE and radiological response (mRECIST). Baseline variables
Table 1 Baseline characteristics of the cohort undergoing repeat TACE therapy

\begin{tabular}{|c|c|}
\hline Baseline Characteristics & Overall cohort $\boldsymbol{n}=292$ \\
\hline Age (years), mean, (SD) & $66(10)$ \\
\hline Male, n (\%) & $254(87)$ \\
\hline Female, n(\%) & $38(13)$ \\
\hline \multicolumn{2}{|l|}{ Ethnicity, n(\%) } \\
\hline Caucasian & $229(78)$ \\
\hline Asian & $51(17)$ \\
\hline Other & $12(4)$ \\
\hline \multicolumn{2}{|l|}{ Aetiology of Liver disease, n(\%) } \\
\hline $\mathrm{HCV} / \mathrm{HBV} / \mathrm{ETOH}$ & 120/58/122 (41/20/42) \\
\hline NAFLD / Haemochromatosis/ other & $67 / 12 / 14(23 / 4 / 5)$ \\
\hline BMI, mean (SD) & $26(24-30)$ \\
\hline \multicolumn{2}{|l|}{ Serum markers, median (IQR) } \\
\hline AFP, ng/ml & $19(5-175)$ \\
\hline$A L T, U / L$ & $49(32-78)$ \\
\hline Albumin, $g / L$ & $34(31-39)$ \\
\hline Bilirubin, $\mu \mathrm{mol} / \mathrm{L}$ & $18(12-27)$ \\
\hline INR & $1.1(1.0-1.3)$ \\
\hline Creatinine, $\mu \mathrm{mol} / \mathrm{L}$ & $75(65-87)$ \\
\hline $\mathrm{Na}, \mathrm{mmol} / \mathrm{L}$ & $139(137-140)$ \\
\hline \multicolumn{2}{|l|}{ Liver function, n (\%) } \\
\hline Portal HTN / Ascites / HE & 253/39/16 (87/13/5) \\
\hline Child Pugh Score (A/B) & 178/88/(61/30) \\
\hline MELD score & $9(7-11)$ \\
\hline ECOG $(0 / 1), n(\%)$ & $127 / 165(43 / 57)$ \\
\hline \multicolumn{2}{|l|}{ Tumour Characteristics } \\
\hline Tumour Nodules (1/2/3/>3), n (\%) & $127 / 65 / 20 / 80(43 / 22 / 7 / 27)$ \\
\hline Tumour Size, cm (median, IQR) & $3.3(2.0-5.0)$ \\
\hline Macrovascular invasion, n (\%) & $9(3)$ \\
\hline Extrahepatic spread, n (\%) & $5(2)$ \\
\hline $\mathrm{BCLC}$ stage $(\mathrm{A} / \mathrm{B} / \mathrm{C}), \mathrm{n}(\%)$ & 166/113/13 (57/39/4) \\
\hline TACE treatments (2/3/>3) n (\%) & $132 / 80 / 80(45 / 27 / 27)$ \\
\hline Type (cTACE / DEB TACE / TAE) & 232/56/3 (79/19/1) \\
\hline \multicolumn{2}{|l|}{ Selectivity } \\
\hline selective /superselective /non selective & 197/48/43 (67/16/15) \\
\hline \multicolumn{2}{|l|}{ mRECIST Response, n (\%) } \\
\hline Complete/Partial & $69 / 127(24 / 43)$ \\
\hline Stable/Progressive & $26 / 22(9 / 8)$ \\
\hline \multicolumn{2}{|l|}{ Adverse Events, n (\%) } \\
\hline Death & $3(1)$ \\
\hline Post TACE syndrome/Decompensation & $38 / 4(13 / 1)$ \\
\hline Renal dysfunction/other & $3 / 12(1 / 4)$ \\
\hline Post TACE Treatment, n (\%) & $59(20)$ \\
\hline Resection/Ablation/PEI/SIRT & $8 / 33 / 11 / 9(3 / 11 / 4 / 3)$ \\
\hline
\end{tabular}




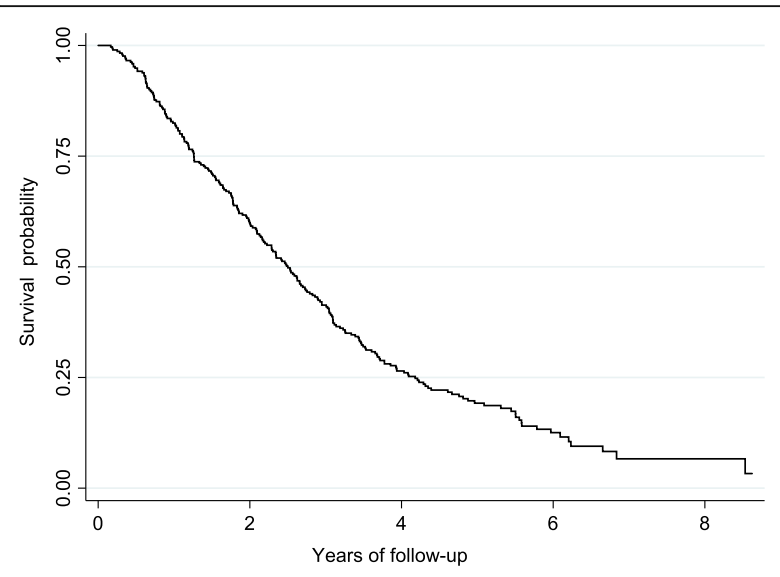

Fig. 1 Kaplan Meier survival analysis of the overall cohort undergoing repeat TACE $(n=292)$

pre-initial TACE associated with improved survival in patients undergoing repeat TACE included single tumour $(p=0.043)$, BCLC stage A $(p=0.026)$ and higher serum albumin $(p<0.001)$ (Table $2 \mathrm{a})$. In contrast, variables reflective of lower hepatic reserve prior to initial and repeat TACE including higher CP score $(p<0.001)$, serum bilirubin $(p<0.001)$, liver decompensation $(p<0.001)$ and ascites $(p<0.001)$ were significantly associated with reduced OS. Of note, renal dysfunction following the second TACE was associated with the highest risk of mortality [HR 3.46 (1.07-11.19), $p=0.035$ ] (Table 2b).

Analysis of serum AFP as a continuous variable demonstrated a higher serum AFP following initial TACE was associated with lower survival $(p<0.001)$ in patients undergoing repeat TACE (data not shown). For increased interpretability of $\mathrm{HR}$ and $\mathrm{CI}$ the application of serum cut-off levels of $200 \mathrm{ng} / \mathrm{ml}$ and $400 \mathrm{ng} / \mathrm{ml}$, demonstrated a significant relationship between both pre and post treatment serum AFP and overall survival (Table 3).

\section{Multivariate analysis}

On multivariate analysis, factors significantly associated with lower survival in patients undergoing repeat TACE included an increase in number of tumour nodules at baseline $(p=0.02)$, a serum AFP $\geq 200 \mathrm{ng} / \mathrm{ml}(p=0.001)$ and higher bilirubin following initial TACE $(p=0.007)$, and liver decompensation following repeat TACE ( $\mathrm{p}=$ 0.001) (Table 4).

\section{Relationship between AFP and overall survival}

On further subgroup analysis patients with a higher serum AFP $\geq 200 \mathrm{ng} / \mathrm{ml}$ following initial TACE had a significantly lower overall survival with median OS of 18.2 months (IQR 9.2 to 26.1) compared to those with serum AFP $<200 \mathrm{ng} / \mathrm{ml}$ of 31.1 months (IQR 18.7 to
55.4) (Fig. 2). Further comparative analysis of the characteristics of these two subgroups (Table 5) found that patients with AFP $\geq 200 \mathrm{ng} / \mathrm{ml}$ had greater tumour burden at baseline as identified by BCLC stage C $(p=0.017)$, larger mean tumour size $(p=0.002)$, and macrovascular invasion $(p=0.035)$ compared to patients with $\mathrm{AFP}<200$ $\mathrm{ng} / \mathrm{ml}$ following initial TACE. In comparison, patients with serum AFP $<200 \mathrm{ng} / \mathrm{ml}$ were less likely to have underlying $\mathrm{HCV}(p=0.004)$ or $\mathrm{HBV}(0.05)$, higher rates of T2DM $(p=0.05)$ and lower inflammatory response following TACE with lower serum neutrophils ( $p=$ $0.001)$ and $\operatorname{ALT}(p=0.03)$.

To further explore the relationship between OS and AFP levels, we analysed the survival of patients according to the pattern of change in serum AFP levels $<$ and $\geq 200 \mathrm{ng} / \mathrm{ml}$ pre- and post-initial TACE. Notably, the median survival of patients with an AFP $\geq 200 \mathrm{ng} / \mathrm{ml}$ both pre- and post-initial was similar to subjects whose level fell below $200 \mathrm{ng} / \mathrm{ml}$ after TACE (18.2 vs 19.9 months) (Table 6). In comparison, the median OS of patients whose AFP remained $<200 \mathrm{ng} / \mathrm{ml}$ both pre- and post-initial TACE was significantly higher at 34.7 months compared to the groups whose AFP level was either $\geq 200 \mathrm{ng} / \mathrm{ml}$ at baseline or increased to $\geq 200 \mathrm{ng} / \mathrm{ml}$ after initial TACE $(p=0.0001)$ (Table 6).

\section{Discussion}

TACE is an effective treatment in eligible patients with uHCC, however the majority of patients treated with TACE will require repeat therapy due to a partial response or tumour recurrence. Treatment outcomes after TACE are influenced by both the severity of underlying liver dysfunction and tumour burden [1-3, 32], and as such the indications and criteria for repeat TACE remain variably defined and adopted in International guidelines $[5,26,33,34]$. We therefore explored the factors associated with overall survival in patients having repeat TACE in a real-world multicenter cohort focusing particularly on the prognostic role of serum AFP level.

Serum AFP as a marker of tumour burden has been previously proposed as a prognostic marker in patients undergoing TACE for uHCC [35-38]. However, the prognostic role of serial changes in serum AFP levels following TACE has been controversial as not all HCC produce AFP, and false positive results not infrequently occur such as in active viral hepatitis [36, 39-41]. Consequently, a wide variety of serum cut off values have been postulated ranging from 20 to $400 \mathrm{ng} / \mathrm{ml}$, as well as variations in serum AFP response ranging from 20 to $50 \%$ based on the AUROC of the derivation cohort [42-48]. Notably, application of these percentage change values in pre and post treatment AFP had no significant prognostic effect on OS in our cohort, and may reflect the inherent differences in our characteristics 
Table 2 Univariate analysis of variables associated with overall survival in patients undergoing repeat TACE, with baseline variables (a) and subsequent to initial TACE (b)

\begin{tabular}{|c|c|c|c|c|}
\hline & \multicolumn{2}{|c|}{ Overall cohort $\boldsymbol{n}=292$} & \multirow[b]{2}{*}{ Higher 95\% Cl } & \multirow[b]{2}{*}{$\boldsymbol{P}$ value } \\
\hline & Hazard Ratio & Lower 95\% Cl & & \\
\hline \multicolumn{5}{|l|}{ Pre -TACE } \\
\hline \multicolumn{5}{|l|}{ Variable } \\
\hline Single Tumour & 0.76 & 0.59 & 1.00 & 0.043 \\
\hline Albumin, $g / L$ & 0.96 & 0.94 & 0.98 & $<0.001$ \\
\hline Bilirubin, $\mu \mathrm{mol} / \mathrm{L}$ & 1.02 & 1.01 & 1.03 & $<0.001$ \\
\hline Ascites & 1.94 & 1.35 & 2.78 & $<0.001$ \\
\hline Hepatic Encephalopathy & 1.70 & 0.99 & 2.90 & 0.048 \\
\hline $\mathrm{BCLC}$ stage $\mathrm{A}$ & 0.75 & 0.58 & 0.97 & 0.026 \\
\hline BCLC stage $B$ & 1.36 & 1.04 & 1.77 & 0.020 \\
\hline Child Pugh Score (5/6/7/8/9) & 1.25 & 1.13 & 1.39 & $<0.001$ \\
\hline AFP $\geq 200 \mathrm{ng} / \mathrm{ml}$ & 1.48 & 1.07 & 2.04 & 0.015 \\
\hline \multicolumn{5}{|l|}{ Post-TACE } \\
\hline \multicolumn{5}{|l|}{ Variable } \\
\hline \multicolumn{5}{|l|}{ Post 1st TACE } \\
\hline AFP $\geq 200 \mathrm{ng} / \mathrm{ml}$ & 2.19 & 1.43 & 3.36 & $<0.001$ \\
\hline Albumin, g/L & 0.95 & 0.93 & 0.98 & $<0.001$ \\
\hline Bilirubin, $\mu \mathrm{mol} / \mathrm{L}$ & 1.02 & 1.01 & 1.03 & $<0.001$ \\
\hline $\mathrm{Na}, \mathrm{mmol} / \mathrm{L}$ & 0.95 & 0.91 & 0.99 & 0.010 \\
\hline INR & 1.70 & 1.12 & 2.59 & 0.012 \\
\hline MELD score & 1.07 & 1.02 & 1.11 & 0.004 \\
\hline Child Pugh Score (5/6/7/8/9) & 1.29 & 1.16 & 1.43 & $<0.001$ \\
\hline Ascites & 1.66 & 1.17 & 2.35 & 0.004 \\
\hline \multicolumn{5}{|l|}{ Post 2nd TACE } \\
\hline Decompensation & 3.39 & 1.85 & 6.21 & $<0.001$ \\
\hline Renal dysfunction & 3.46 & 1.07 & 11.19 & 0.035 \\
\hline Combination therapy & 0.65 & 0.46 & 0.91 & 0.011 \\
\hline Ablation & 0.56 & 0.35 & 0.88 & 0.011 \\
\hline Resection & 0.27 & 0.10 & 0.76 & 0.011 \\
\hline
\end{tabular}

at baseline and also the inability of the delta value to capture the wide variations in serum AFP levels associated with HCC [49].

In contrast several recent studies including a metaanalysis have demonstrated a significant association of specific serum levels of AFP with HCC treatment outcomes including treatment response and overall survival [43, 50, 51]. In a recent prognostic model Wang et al. found the serum AFP of $400 \mathrm{ng} / \mathrm{ml}$ was a useful cut off value in a population with predominantly HBV related liver disease [38, 45]. They found the AFP response following TACE independently associated with prognosis in BCLC stage B patients, however further analysis regarding combination therapy

Table 3 Univariate analysis of pre and post initial TACE serum AFP levels and association with overall survival

\begin{tabular}{|c|c|c|c|c|c|c|}
\hline Variable & $\mathrm{n}$ & $\%$ & Hazard Ratio & Lower $95 \% \mathrm{Cl}$ & Higher $95 \% \mathrm{Cl}$ & $P$ value \\
\hline Baseline AFP $\geq 200 \mathrm{ng} / \mathrm{ml}$ & 260 & $23 \%$ & 1.48 & 1.07 & 2.04 & 0.015 \\
\hline Post initial TACE AFP $\geq 200 \mathrm{ng} / \mathrm{ml}$ & 177 & $17 \%$ & 2.19 & 1.43 & 3.36 & $<0.001$ \\
\hline Baseline AFP $\geq 400 \mathrm{ng} / \mathrm{ml}$ & 260 & $17 \%$ & 1.36 & 0.95 & 1.95 & 0.088 \\
\hline Post Initial TACE AFP $\geq 400 \mathrm{ng} / \mathrm{ml}$ & 177 & $13 \%$ & 2.41 & 1.49 & 3.90 & $<0.001$ \\
\hline
\end{tabular}


Table 4 Multivariate analysis of variables associated with overall survival in patients undergoing repeat TACE

\begin{tabular}{lllll}
\hline $\begin{array}{l}\text { Overall cohort } \boldsymbol{n}=292 \\
\text { Variable }\end{array}$ & Hazard Ratio & Lower $95 \% \mathrm{Cl}$ & Higher $95 \% \mathrm{Cl}$ & $\boldsymbol{P}$ value \\
\hline Baseline tumour number, 1, 2,3, > & 1.18 & 1.03 & 1.36 & 1.03 \\
Bilirubin post TACE 1 & 1.02 & 1.00 & 3.40 & 0.020 \\
AFP $\geq 200 \mathrm{ng} / \mathrm{ml}$ post TACE 1 & 2.13 & 1.34 & 10.89 & 0.001 \\
Decompensation post TACE 2 & 4.50 & 1.86 & 0.001 \\
\hline
\end{tabular}

with other treatments such as ablation or systemic therapies was not available.

When applied to our cohort, we found serum AFP cut off level of $200 \mathrm{ng} / \mathrm{ml}$ had the greatest stratification compared to an AFP $<20 \mathrm{ng} / \mathrm{ml}$ that was seen in $135(52 \%)$ and AFP $<400 \mathrm{ng} / \mathrm{ml}$ in 215 (83\%) of patients. This AFP value has the potential advantage over the lower cut off value of $<20 \mathrm{ng} / \mathrm{ml}$ in being less likely to include those with an elevated level due to active liver disease such as such as with chronic viral hepatitis [36, 41]. A serum AFP $<200 \mathrm{ng} / \mathrm{ml}$ was a significant prognostic marker both pre and post initial TACE associated with better overall survival outcomes (Fig. 2). Patients that maintained an AFP $<200 \mathrm{ng} / \mathrm{ml}$ at baseline and following initial TACE had a significantly better survival outcome $(p=0.0001)$ compared to patients that had a higher baseline AFP $\geq 2$ $00 \mathrm{ng} / \mathrm{ml}$ regardless of a post treatment change in levels. The poorer prognosis in patients with AFP $\geq 200 \mathrm{ng} / \mathrm{ml}$ following TACE may relate to the greater tumour burden at baseline including tumour size $(p=0.002)$ and macrovascular invasion $(p=0.035)$ along with greater inflammatory response to treatment with higher serum ALT ( $p=$ $0.03)$ and neutrophil count $(p=0.001)$. Further detailed analysis of serum AFP pre and post TACE is limited by small number of patients in each subgroup.

Our results are consistent with recent updates in international guidelines $[26,52]$ that have endorsed the

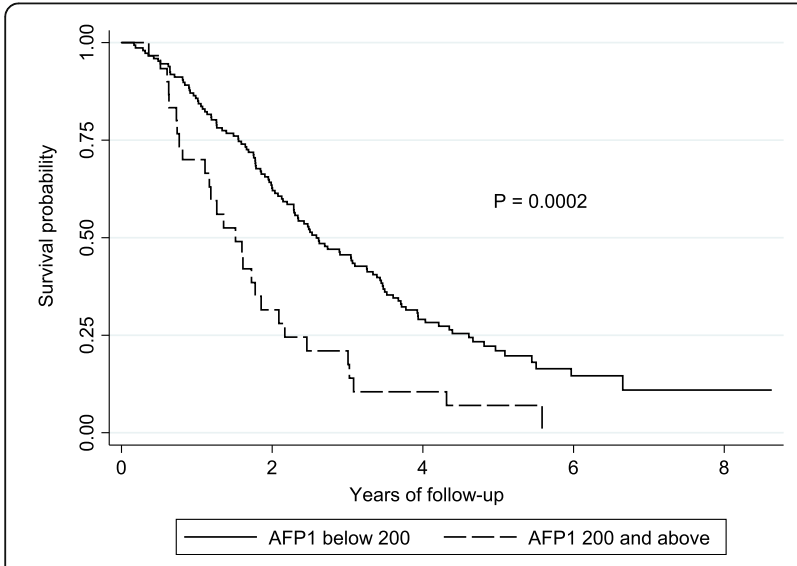

Fig. 2 Kaplan Meier survival analysis of patients with an serum AFP above or below $200 \mathrm{ng} / \mathrm{ml}$ following initial TACE (AFP1) revised cut off of $200 \mathrm{ng} / \mathrm{ml}$ from the previously used $400 \mathrm{ng} / \mathrm{ml}$ due to superior sensitivity and specificity and nearly $99 \%$ positive predictive value $[36,49,53]$. In particular explant studies have demonstrated higher AFP levels $\geq 200 \mathrm{ng} / \mathrm{ml}$ are associated with higher risk of both microvascular and macrovascular invasion, along with poorly differentiated tumours as was demonstrated in our analysis (Table 3) [21, 54]. However, the reduced availability of repeat AFP data in $61 \%$ of our overall cohort limits the generalisability of our findings particularly in cases of non-AFP producing HCC.

Along with AFP level, we found like others on multivariate analysis that markers of both hepatic reserve and tumour burden are key prognostic markers being associated with poorer survival following repeat TACE [14, 55-59]. In particular, decreasing liver reserve had the greatest impact on mortality in our cohort with post TACE liver failure and decompensation associated with the highest risk of reduced survival [HR 4.50, (95\% CI $1.86-10.89), p=0.001],(p=0.001)$. Although this occurred in only $1 \%$ of our patients and is generally thought to be low in incidence (2-7\%) [60-62], the frequency of liver decompensation may be as high as $18 \%$ following TACE depending on the definition used [30, 63-65]. We also found like others that decline in liver function as measured by higher serum bilirubin prior to repeat TACE was associated with reduced survival [66-68]. This again highlights the prognostic importance of liver reserve following TACE because discontinuation of TACE due to liver decompensation and/or biochemical decline carries a poorer prognosis than when it is due to radiological progression. Indeed, most patients with significant hyperbilirubinaemia are unsuitable for or intolerant of further therapies such as systemic therapy and are managed with best supportive care [69-71].

In addition, the number of tumour nodules prior to initial TACE was a significant and independent prognostic marker following repeat TACE in our cohort being associated with a higher risk of mortality. This is similar to the findings of several previous studies $[57,72,73]$. Furthermore, greater tumour size at baseline was significantly associated with higher serum AFP $\geq 200 \mathrm{ng} / \mathrm{ml}$ following initial TACE which was one of the key prognostic determinants associated with lower OS on multivariate analysis (Table 4). 
Table 5 Characteristics of patients following initial TACE with AFP $\geq 200 \mathrm{ng} / \mathrm{ml} \mathrm{vs} .<200 \mathrm{ng} / \mathrm{ml}$

\begin{tabular}{|c|c|c|c|c|c|}
\hline \multicolumn{6}{|c|}{ Repeat serum AFP subgroup $\boldsymbol{n}=177$} \\
\hline Variable & $n$ & AFP $<200 \mathrm{ng} / \mathrm{ml}$ & $n$ & AFP $\geq 200 \mathrm{ng} / \mathrm{ml}$ & $\boldsymbol{P}$ value \\
\hline \multicolumn{6}{|l|}{ Pre-TACE, \% (n) } \\
\hline Caucasian & 147 & $83.7 \%(123)$ & 30 & $63.3 \%(19)$ & 0.011 \\
\hline $\mathrm{HCV}$ & 147 & $41.5 \%(61)$ & 30 & $70 \%(21)$ & 0.004 \\
\hline HBV & 147 & $17.7 \%(26)$ & 30 & $33.3 \%(10)$ & 0.05 \\
\hline T2DM & 147 & $34.7 \%(51)$ & 30 & $16.7 \%(5)$ & 0.05 \\
\hline $\mathrm{BCLC}$ stage $\mathrm{C}$ & 147 & $2 \%(3)$ & 30 & $13.3 \%(4)$ & 0.017 \\
\hline Macrovascular invasion & 147 & $1.4 \%(2)$ & 30 & $10 \%(3)$ & 0.035 \\
\hline tumour size, (cm), mean (SD) & 147 & $3.84(2.55)$ & 30 & $5.64(3.89)$ & 0.002 \\
\hline \multicolumn{6}{|l|}{ Post initial TACE, median (IQR) } \\
\hline Neutrophils, $\times 10 \wedge 9 / L$ & 91 & $2.9[2.3-3.72]$ & 23 & $4.2[2.9-5.1]$ & 0.001 \\
\hline $\mathrm{ALT}, \mathrm{U} / \mathrm{L}$ & 146 & $38.5[24-72]$ & 29 & 65 [34-100] & 0.03 \\
\hline $\mathrm{Na}, \mathrm{mmol} / \mathrm{L}$ & 145 & 138 [136-140] & 28 & 137 [135-139] & 0.048 \\
\hline
\end{tabular}

As noted above an important limitation of our study was the reduced availability of serial AFP levels before and after the initial TACE to explore the relationship with survival further. However, there was only minimal differences in the characteristics in those without follow up AFP levels, with lower rates of $\mathrm{HCV}$ infection ( $p=$ $0.024)$, higher NAFLD $(p=0.03)$, and higher proportion of single HCC $(\mathrm{p}=0.03)$ (data not shown). Other study limitations include the retrospective analysis of data with resultant variations in the timing of serum collection pre and post TACE as well as variations in on-site specific protocols, and this may impact on the interpretation of results that are influenced by post treatment hepatic dysfunction and inflammation such as serum AFP [36, 41].

Our study also includes patients undergoing combination therapies with TACE and a small number of BCLC stage C (4\%) patients that underwent TACE outside of current guidelines, consistent with contemporary realworld studies analysing global patterns of TACE utilisation $[15,16]$. Despite these limitations this is a large study analysing prognostic factors in patients undergoing repeat TACE on demand for uHCC over a significant period of 6 years across six large tertiary referral centres. As such these results have greater clinical relevancy to

Table 6 Median survival time by AFP level of $200 \mathrm{ng} / \mathrm{ml}$ at baseline and post initial TACE

\begin{tabular}{llll}
\hline AFP groups & $\mathrm{n}$ & $\begin{array}{l}\text { Median Survival time, } \\
\text { months }(\text { IQR })\end{array}$ & $\boldsymbol{P}$ value \\
\hline AFPO $<200$ and AFP1 $<200$ & 135 & $34.7(19.9-56.1)$ & 0.0001 \\
AFPO $<200$ and AFP1 $\geq 200$ & 5 & $19.4(14.2-29.6)$ & \\
AFPO $\geq 200$ and AFP1 $<200$ & 12 & $19.9(13.3-27.7)$ & \\
AFPO $\geq 200$ and AFP1 $\geq 200$ & 25 & $18.2(9.2-26.1)$ & \\
\hline
\end{tabular}

current clinical practice as the data incorporates variations in patient selection, TACE type (conventional or DEB), and technique (selective or super selective).

\section{Conclusions}

Patient selection for repeat TACE requires a careful balance between the risk of complications, and benefits, with evaluation of both pre and post treatment factors associated with poor outcomes. These include higher baseline tumour burden, and decline in liver reserve. In particular, serum AFP is a useful prognostic marker for risk stratification, with an $\mathrm{AFP} \geq 200 \mathrm{ng} / \mathrm{ml}$ post initial TACE associated with significantly poorer outcomes in those undergoing repeat TACE.

\section{Appendix mRECIST Definition [31]}

Radiological response will be defined according to standard EASL criteria using modified RECIST (mRECIST) criteria as assessed by triphasic CT scan and/or MRI scan and include the following:

Complete response (CR): Disappearance of any intratumoural arterial enhancement in all target lesions

Partial response (PR): At least a 30\% decrease in the sum of the diameters of viable (enhancement in the arterial phase) target lesions

Stable disease (SD): Any cases that do not qualify for either PR or progressive disease (PD)

Progressive disease (PD): An increase of at least 20\% in the sum of the diameters of viable (enhancing) target lesions, taking as reference the smallest sum of the diameters of viable (enhancing) target lesions recorded since treatment started. 


\section{Abbreviations}

AFP: Alpha-fetoprotein; BCLC: Barcelona Clinic Liver Cancer; Cl: Confidence interval; CPS: Child Pugh score; CR: Complete response; DEB: Drug-eluting bead; ECOG: Eastern Cooperative Oncology Group; EHS: Extra hepatic spread; HBV: Hepatitis B virus; HCC: Hepatocellular carcinoma; HCV: Hepatitis C virus; HR: Hazard ratio; INR: International normalised ration; KM: Kaplan-Meier; MDT: Multidisciplinary team; mRECIST: Modified Response Evaluation Criteria in Solid Tumours; NAFLD: Non-alcoholic fatty liver disease; OS: Overall survival; PD: Progressive disease; PEl: Percutaneous ethanol injection; PR: Partial response; PTS: Post TACE syndrome; RCT: Randomised controlled trial; SD: Stable disease; SIRT: Selective internal radiation therapy; TACE: Transarterial chemoembolisation; MVI: Macrovascular invasion

\section{Acknowledgements}

We thank Mr. Paul O'Neil, Ms. Virginia Bird, Ms. Pam Crest, Ms. Angela Li, Ms. Anne Dowling, and Ms. Carol McCrae for their assistance with data collation.

\section{Authors' contributions}

GM, AD and SKR contributed to the study design; GM and all co-authors contributed to data acquisition and collation; EP performed statistical analysis; WC, JK, AJ, BM, BGL, PS, AB, JB, MG, VR and MS contributed to the assessment of pre and post treatment imaging; $A D, J L, P G, S S, A T, A N$, and SKR facilitated site specific ethics approval and data collation at each participating tertiary centre. GM, EP and SKR had full access to all the data in the study and take responsibility for the integrity of the data and the accuracy of the data analysis. The author(s) read and approved the final manuscript.

\section{Funding}

GM was supported by an Australian Government Research Training Program (RTP) Scholarship, Monash University. The funding body played no role in a) the design of the study; b) the collection, analysis, and interpretation of the data; and c) writing of the manuscript.

\section{Availability of data and materials}

The datasets generated and analysed during the current study are available from the corresponding author on reasonable request.

\section{Ethics approval and consent to participate}

This study was approved by the institutional Ethics Committees of all six participating sites including Monash Health, Alfred Health, Austin Health, Eastern Health, Royal Melbourne Hospital and St. Vincent's Hospital. A Memorandum of Understanding was undertaken with the lead site of Monash Health for sharing and collation of data, research project application no. $16241 \mathrm{Q}$.

\section{Consent for publication}

Not applicable.

\section{Competing interests}

The authors declare that they have no competing interests.

\footnotetext{
Author details

${ }^{1}$ Gastroenterology, Monash Health, Melbourne, Australia. ${ }^{2}$ School of Public Health and Preventive Medicine, Monash University, Melbourne, Australia. ${ }^{3}$ Radiology, Alfred Health, Melbourne, Australia. ${ }^{4}$ Radiology, St. Vincent's Hospital, Melbourne, Australia. ${ }^{5}$ Radiology, Royal Melbourne Hospital, Melbourne, Australia. ${ }^{6}$ Radiology, Monash Health Eastern Health, Melbourne, Australia. ${ }^{7}$ Radiology, Austin Health, Melbourne, Australia. ${ }^{8}$ Radiology, Eastern Health, Melbourne, Australia. ${ }^{9}$ Department of Gastroenterology, The Alfred Hospital, 55 Commercial Rd, Melbourne 3004, Australia. ${ }^{10}$ Gastroenterology, Austin Health, Melbourne, Australia. ${ }^{11}$ Gastroenterology, Royal Melbourne Hospital, Melbourne, Australia. ${ }^{12}$ Gastroenterology, St. Vincent's Hospital, Melbourne, Australia. ${ }^{13}$ Gastroenterology, Eastern Health, Melbourne, Australia.
}

Received: 9 January 2020 Accepted: 30 March 2020

Published online: 29 May 2020

\section{References}

1. White JA, Redden DT, Bryant M, et al. Predictors of repeat transarterial chemoembolisation in the treatment of hepatocellular carcinoma. Hpb. 2014;16(12):1095-101. https://doi.org/10.1111/hpb.12313.

2. Syha R, Ketelsen D, Heller S, et al. Hepatocellular carcinoma. Eur J Gastroen Hepat. 2012;24(11):1325-32. https://doi.org/10.1097/meg. ob013e32835724bc

3. Jaeger HJ, Mehring U-M, Castañeda F, et al. Sequential transarterial chemoembolisation for unresectable advanced hepatocellular carcinoma. Cardiovasc Inter Rad. 1996;19(6):388-96. https://doi.org/10.1007/bf02577625.

4. Golfieri R, Renzulli M, Mosconi C, et al. Hepatocellular carcinoma responding to Superselective Transarterial chemoembolisation. J Vasc Interv Radiol. 2013;24(4):509-17. https://doi.org/10.1016/j.jvir.2012.12.013.

5. Cheng A, Amarapurkar D, Chao Y, et al. Re-evaluating transarterial chemoembolisation for the treatment of hepatocellular carcinoma: consensus recommendations and review by an international expert panel. Liver Int. 2014;34(2):174-83. https://doi.org/10.1111/liv.12314.

6. Raoul J-L, Gilabert M, Piana G. How to define Transarterial chemoembolisation failure or refractoriness: a European perspective. Liver Cancer. 2014;3(2):119-24. https://doi.org/10.1159/000343867.

7. Sieghart W, Hucke F, Peck-Radosavljevic M. Transarterial chemoembolisation: modalities, indication, and patient selection. J Hepatol. 2015;62(5):1187-95. https://doi.org/10.1016/j.jhep.2015.02.010.

8. Hucke F, Sieghart W, Pinter M, et al. The ART-strategy: sequential assessment of the ART score predicts outcome of patients with hepatocellular carcinoma re-treated with TACE. J Hepatol. 2014;60(1):118-26. https://doi. org/10.1016/j.jhep.2013.08.022.

9. Adhoute X, Penaranda G, Naude S, et al. Retreatment with TACE: the ABCR SCORE, an aid to the decision-making process. J Hepatol. 2015;62(4):855-62. https://doi.org/10.1016/j.jhep.2014.11.014.

10. Kim H-D, An J, Kim J, et al. Impact of the interval between Transarterial chemoembolisation sessions on survival in patients with Unresectable hepatocellular carcinoma. J Vasc Interv Radiol. 2016;27(4):504-13. https://doi. org/10.1016/j.jvir.2015.12.005.

11. Terzi E, Golfieri R, Piscaglia F, et al. Response rate and clinical outcome of HCC after first and repeated CTACE performed "on demand.". J Hepatol. 2012;57(6):1258-67. https://doi.org/10.1016/j.jhep.2012.07.025.

12. Pinato D, Howell J, Ramaswami R, Sharma R. Review article: delivering precision oncology in intermediate-stage liver cancer. Alimentary Pharmacol Ther. 2017;45(12):1514-23. https://doi.org/10.1111/apt.14066.

13. Piscaglia F, Ogasawara S. Patient selection for Transarterial chemoembolisation in hepatocellular carcinoma: importance of benefit/risk assessment. Liver Cancer. 2018;7(1):104-19. https://doi.org/10.1159/ 000485471.

14. Takayasu K, Arii S, Ikai I, et al. Prospective cohort study of Transarterial chemoembolisation for Unresectable hepatocellular carcinoma in 8510 patients. Gastroenterology. 2006;131(2):461-9. https://doi.org/10.1053/j. gastro.2006.05.021.

15. Yen $C$, Sharma R, Rimassa $L$, et al. Treatment stage migration maximizes survival outcomes in patients with hepatocellular carcinoma treated with Sorafenib: An observational study. Liver Cancer. 2017;6(4):313-24. https://doi org/10.1159/000480441.

16. Roberts SK, Gazzola A, Lubel J, et al. Treatment choice for early-stage hepatocellular carcinoma in real-world practice: impact of treatment stage migration to transarterial chemoembolisation and treatment response on survival. Scand J Gastroentero. 2018;53(10-11):1-8. https://doi.org/10.1080/ 00365521.2018 .1517277$.

17. Otto $G$, Herber $S$, Heise $M$, et al. Response to transarterial chemoembolisation as a biological selection criterion for liver transplantation in hepatocellular carcinoma. Liver Transplant. 2006;12(8): 1260-7. https://doi.org/10.1002/lt.20837.

18. Toso C, Asthana S, Bigam DL, Shapiro JA, Kneteman NM. Reassessing selection criteria prior to liver transplantation for hepatocellular carcinoma utilizing the scientific registry of transplant recipient's database. Hepatology. 2009;49(3):832-8. https://doi.org/10.1002/hep.22693.

19. Shan Y, Huang Y, Xie Y, et al. Angiogenesis and clinicopathologic characteristics in different hepatocellular carcinoma subtypes defined by 
EpCAM and a-fetoprotein expression status. Med Oncol. 2010;28(4):1012-6. https://doi.org/10.1007/s12032-010-9600-6.

20. Llovet JM, Montal R, Sia D, Finn RS. Molecular therapies and precision medicine for hepatocellular carcinoma. Nat Rev Clin Oncol. 2018;15(10):118. https://doi.org/10.1038/s41571-018-0073-4.

21. Fujiki M, Takada Y, Ogura Y, et al. Significance of des-gamma-Carboxy Prothrombin in selection criteria for living donor liver transplantation for hepatocellular carcinoma. Am J Transplant. 2009;9(10):2362-71. https://doi. org/10.1111/j.1600-6143.2009.02783.x.

22. Hoshida $Y$, Nijman SM, Kobayashi M, et al. Integrative transcriptome analysis reveals common molecular subclasses of human hepatocellular carcinoma. Cancer Res. 2009;69(18):7385-92. https://doi.org/10.1158/ 0008-5472.can-09-1089.

23. Toro A, Ardiri A, Mannino M, et al. Effect of pre- and post-treatment afetoprotein levels and tumour size on survival of patients with hepatocellular carcinoma treated by resection, transarterial chemoembolisation or radiofrequency ablation: a retrospective study. BMC Surg. 2014;14(1):40. https://doi.org/10.1186/1471-2482-14-40.

24. Izumoto H, Hiraoka A, Ishimaru Y, et al. Validation of newly proposed time to Transarterial chemoembolisation progression in intermediate-stage hepatocellular carcinoma cases. Oncology. 2017;93(Suppl. 1):120-6. https:// doi.org/10.1159/000481242

25. Lee $\mathrm{Y}-\mathrm{H}$, Hsu C-Y, Huang Y-H, et al. Vascular invasion in hepatocellular carcinoma. J Clin Gastroenterol. 2014;48(8):734-41. https://doi.org/10.1097/ mcg.0b013e3182a8a254.

26. Marrero JA, Kulik LM, Sirlin CB, et al. Diagnosis, staging, and Management of Hepatocellular Carcinoma: 2018 practice guidance by the American Association for the Study of Liver Diseases. Hepatology. 2018;68(2):723-50. https://doi.org/10.1002/hep.29913.

27. Mgaieth $\mathrm{S}$, Kemp W, Gow P, et al. Impact of viral hepatitis aetiology on survival outcomes in hepatocellular carcinoma: a large multicentre cohort study. J Viral Hepatitis. 2017;24(11):982-9. https://doi.org/10.1111/jvh.12717.

28. Ge PS, Runyon BA. Treatment of patients with cirrhosis. New Engl J Medicine. 2016;375(8):767-77. https://doi.org/10.1056/nejmra1504367.

29. Moreau R, Jalan R, Gines P, et al. Acute-on-Chronic Liver Failure Is a Distinct Syndrome That Develops in Patients With Acute Decompensation of Cirrhosis. Gastroenterology. 2013;144(7):1426-1437.e9. https://doi.org/10. 1053/.j.gastro.2013.02.042

30. Lencioni R, de Baere T, Soulen MC, Rilling WS, Geschwind JH. Lipiodol transarterial chemoembolisation for hepatocellular carcinoma: a systematic review of efficacy and safety data. Hepatology. 2016;64(1):106-16. https:// doi.org/10.1002/hep.28453.

31. Galle PR, Forner A, Llovet JM, et al. EASL Clinical Practice Guidelines: Management of hepatocellular carcinoma. J Hepatol. 2018;69:182-236. https://doi.org/10.1016/j.jhep.2018.03.019

32. Eltawil KM, Berry R, Abdolell M, Molinari M. Analysis of survival predictors in a prospective cohort of patients undergoing transarterial chemoembolisation for hepatocellular carcinoma in a single Canadian Centre. Hpb. 2012;14(3):162-70. https://doi.org/10.1111/j.1477-2574. 2011.00420.x.

33. Kokudo N, Takemura N, Hasegawa K, et al. Clinical practice guidelines for hepatocellular carcinoma: the Japan Society of Hepatology 2017 (4th JSHHCC guidelines) a 2019 update. Hepatol Res. 2019;49(10):1109-13. https:// doi.org/10.1111/hepr.13411.

34. Galle PR, Foerster F, Kudo M, et al. Biology and significance of alphafetoprotein in hepatocellular carcinoma. Liver Int. 2019;39(12):2214-29. https://doi.org/10.1111/liv.14223.

35. Amarapurkar D, Han K-H, Chan H, Ueno Y. On of carcinoma T. application of surveillance programs for hepatocellular carcinoma in the Asia-Pacific region. J Gastroen Hepatol. 2009;24(6):955-61. https://doi.org/10.1111/j. 1440-1746.2009.05805.x.

36. Trevisani F, D'Intino P, Morselli-Labate A, et al. Serum a-fetoprotein for diagnosis of hepatocellular carcinoma in patients with chronic liver disease: influence of HBsAg and anti-HCV status. J Hepatol. 2001;34(4):570-5. https:// doi.org/10.1016/s0168-8278(00)00053-2.

37. Memon K, Kulik L, Lewandowski RJ, et al. Alpha-fetoprotein response correlates with EASL response and survival in solitary hepatocellular carcinoma treated with transarterial therapies: a subgroup analysis. J Hepatol. 2012;56(5):1112-20. https://doi.org/10.1016/j.jhep.2011.11.020.

38. Liu G, Ouyang Q, Xia F, et al. Alpha-fetoprotein response following transarterial chemoembolisation indicates improved survival for intermediate-stage hepatocellular carcinoma. Hpb. 2018;21:107-13. https:// doi.org/10.1016/j.hpb.2018.06.1800

39. Llovet JM, Real M, Montaña X, et al. Arterial embolisation or chemoembolisation versus symptomatic treatment in patients with unresectable hepatocellular carcinoma: a randomised controlled trial. Lancet. 2002;359(9319):1734-9. https://doi.org/10.1016/s01406736(02)08649-x.

40. Lo C, Ngan H, Tso W, et al. Randomized controlled trial of transarterial lipiodol chemoembolisation for unresectable hepatocellular carcinoma. Hepatology. 2002;35(5):1164-71. https://doi.org/10.1053/jhep.2002.33156.

41. Oka H, Tamori A, Kuroki T, Kobayashi K, Yamamoto S. Prospective study of a-fetoprotein in cirrhotic patients monitored for development of hepatocellular carcinoma. Hepatology. 1994;19(1):61-6. https://doi.org/10. 1002/hep.1840190111.

42. Liu L, Zhao Y, Jia J, et al. The prognostic value of alpha-fetoprotein response for advanced-stage hepatocellular carcinoma treated with Sorafenib combined with Transarterial chemoembolisation. Sci Rep-uk. 2016;6(1): 19851. https://doi.org/10.1038/srep19851.

43. Wang $Y$, Chen $Y$, Ge N, et al. Prognostic significance of alpha-fetoprotein status in the outcome of hepatocellular carcinoma after treatment of Transarterial chemoembolisation. Ann Surg Oncol. 2012;19(11):3540-6. https://doi.org/10.1245/s10434-012-2368-5.

44. Sanai FM, Sobki S, Bzeizi Kl, et al. Assessment of alpha-fetoprotein in the diagnosis of hepatocellular carcinoma in middle eastern patients. Digest Dis Sci. 2010;55(12):3568-75. https://doi.org/10.1007/s10620-010-1201-X.

45. Wang Q, Xia D, Bai W, et al. Development of a prognostic score for recommended TACE candidates with hepatocellular carcinoma: a multicentre observational study. J Hepatol. 2019;70:893-903. (Gastroenterology 150 2016). https://doi.org/10.1016/j.jhep.2019.01.013.

46. Riaz A, Ryu RK, Kulik LM, et al. Alpha-fetoprotein response after Locoregional therapy for hepatocellular carcinoma: oncologic marker of radiologic response, progression, and survival. J Clin Oncol. 2009:27(34):5734-42. https://doi.org/10.1200/jco.2009.23.1282.

47. Personeni N, Bozzarelli S, Pressiani T, et al. Usefulness of alphafetoprotein response in patients treated with sorafenib for advanced hepatocellular carcinoma. J Hepatol. 2012;57(1):101-7. https://doi.org/10. 1016/j.jhep.2012.02.016.

48. Xu X-S, Qu K, Liu C, et al. Highlights for \&alpha;fetoprotein in determining prognosis and treatment monitoring for hepatocellular carcinoma. World J Gastroentero. 2012;18(48):7242-50. https://doi.org/10.3748/wjg.v18.i48.7242.

49. Ichikawa T, Machida N, Sasaki H, et al. Early prediction of the outcome using tumour markers and mRECIST in Unresectable hepatocellular carcinoma patients who underwent Transarterial chemoembolisation. Oncology. 2016; 91(6):317-30. https://doi.org/10.1159/000448999.

50. Lee M, Kim S, Kim D, et al. Early on-treatment predictions of clinical outcomes using alpha-fetoprotein and des-gamma-carboxy prothrombin responses in patients with advanced hepatocellular carcinoma. J Gastroen Hepatol. 2012;27(2):313-22. https://doi.org/10.1111/j.1440-1746.2011.06867.x.

51. He C, Peng W, Liu X, Li C, Li X, Wen T-F. Post-treatment alpha-fetoprotein response predicts prognosis of patients with hepatocellular carcinoma. Medicine. 2019;98(31):e16557. https://doi.org/10.1097/md. 0000000000016557.

52. Korean Liver Cancer Study Group (KLCSG); National Cancer Center, Korea (NCC). Korean Liver Cancer Study Group-National Cancer Center Korea practice guideline for the management of hepatocellular carcinoma. Korean J Radiol. 2015;16(3):465-522. https://doi.org/10.3348/kjr.2015.16.3.465.

53. Torzilli G, Minagawa M, Takayama T, et al. Accurate preoperative evaluation of liver mass lesions without fine-needle biopsy. Hepatology. 1999;30(4): 889-93. https://doi.org/10.1002/hep.510300411.

54. Duvoux C, Roudot Thoraval F, Decaens T, et al. Liver Transplantation for Hepatocellular Carcinoma: A Model Including a-Fetoprotein Improves the Performance of Milan Criteria. Gastroenterology. 2012;143(4):986-994.e3. https://doi.org/10.1053/j.gastro.2012.05.052.

55. Douhara A, Namisaki T, Moriya K, et al. Predisposing factors for hepatocellular carcinoma recurrence following initial remission after transcatheter arterial chemoembolisation. Oncol Lett. 2017;14(3):3028-34. https://doi.org/10.3892/ol.2017.6489.

56. Jin Y-J, Chung Y-H, Kim JA, et al. Predisposing factors of hepatocellular carcinoma recurrence following complete remission in response to Transarterial chemoembolisation. Digest Dis Sci. 2013;58(6):1758-65. https:// doi.org/10.1007/s10620-013-2562-8. 
57. Kinugasa H, Nouso K, Takeuchi Y, et al. Risk factors for recurrence after transarterial chemoembolisation for early-stage hepatocellular carcinoma. J Gastroenterol. 2012;47(4):421-6. https://doi.org/10.1007/s00535-011-0492-9.

58. Park W, Chung Y, Kim JA, et al. Recurrences of hepatocellular carcinoma following complete remission by transarterial chemoembolisation or radiofrequency therapy: focused on the recurrence patterns. Hepatol Res. 2013;43(12):1304-12. https://doi.org/10.1111/hepr.12083.

59. Colecchia A, Schiumerini R, Cucchetti A, et al. Prognostic factors for hepatocellular carcinoma recurrence. World J Gastroentero. 2014;20(20): 5935-50. https://doi.org/10.3748/wjg.v20.i20.5935.

60. Marelli L, Stigliano R, Triantos C, et al. Transarterial therapy for hepatocellular carcinoma: which technique is more effective? A systematic review of cohort and randomized studies. Cardiovasc Inter Rad. 2006;30(1):6. https:// doi.org/10.1007/s00270-006-0062-3.

61. Raoul J-L, Sangro B, Forner A, et al. Evolving strategies for the management of intermediate-stage hepatocellular carcinoma: available evidence and expert opinion on the use of transarterial chemoembolisation. Cancer Treat Rev. 2011;37(3):212-20. https://doi.org/10.1016/j.ctrv.2010.07.006.

62. Vogl TJ, Naguib N, Nour-Eldin N-EA, et al. Review on transarterial chemoembolisation in hepatocellular carcinoma: palliative, combined, neoadjuvant, bridging, and symptomatic indications. Eur J Radiol. 2009; 72(3):505-16. https://doi.org/10.1016/j.ejrad.2008.08.007.

63. Hsin I-F, Hsu C-Y, Huang H-C, et al. Liver failure after Transarterial chemoembolisation for patients with hepatocellular carcinoma and ascites. J Clin Gastroenterol. 2011;45(6):556-62. https://doi.org/10.1097/mcg. Ob013e318210ff17.

64. Sun Z, Li G, Ai X, et al. Hepatic and biliary damage after transarterial chemoembolisation for malignant hepatic tumour s: incidence, diagnosis, treatment, outcome and mechanism. Crit Rev Oncol Hemat. 2011;79(2):16474. https://doi.org/10.1016/j.critrevonc.2010.07.019.

65. Clark TW. Complications of hepatic chemoembolisation. Semin Intervent Rad. 2006;23(2):119-25. https://doi.org/10.1055/s-2006-941442

66. Dhanasekaran R, Kooby DA, Staley CA, Kauh JS, Khanna V, Kim HS Prognostic factors for survival in patients with unresectable hepatocellular carcinoma undergoing chemoembolisation with doxorubicin drug-eluting beads: a preliminary study. Hpb. 2010;12(3):174-80. https://doi.org/10.1111/j. 1477-2574.2009.00138x.

67. Han G, Berhane S, Toyoda $\mathrm{H}$, et al. Prediction of survival among patients receiving Transarterial chemoembolisation for hepatocellular carcinoma: a response-based approach. Hepatology. 2019. https://doi.org/10.1002/hep.31022.

68. Toyoda H, Kumada T, Tada T, et al. Differences in the impact of prognostic factors for hepatocellular carcinoma over time. Cancer Sci. 2017;108(12): 2438-44. https://doi.org/10.1111/cas.13406.

69. Labeur TA, Takkenberg RB, Klumben HJ, van Delden OM. Reason of discontinuation after transarterial chemoembolisation influences survival in patients with hepatocellular carcinoma. Hepatology. 2018;68(1):840A-1A Conference: 69th annual meeting of the American Association for the Study of Liver Diseases, AASLD.

70. Prins P, Sharma T, Kim KS, et al. Change in liver function as measured by change of child Pugh score to predict survival in patients with advanced hepatocellular carcinoma (HCC) during the treatment course. J Clin Oncol. 2018;36(4):310

71. Garwood ER, Fidelman N, Hoch SE, Kerlan RK, Yao FY. Morbidity and mortality following transarterial liver chemoembolisation in patients with hepatocellular carcinoma and synthetic hepatic dysfunction. Liver Transplant. 2013;19(2):164-73. https://doi.org/10.1002/tt.23552.

72. Yamakado K, Miyayama S, Hirota S, et al. Subgrouping of intermediate-stage (BCLC stage B) hepatocellular carcinoma based on tumour number and size and child-Pugh grade correlated with prognosis after transarterial chemoembolisation. Jpn J Radiol. 2014;32(5):260-5. https://doi.org/10.1007/ s11604-014-0298-9.

73. Katayama K, Imai T, Abe Y, et al. Number of Nodules but not Size of Hepatocellular Carcinoma Can Predict Refractoriness to Transarteria Chemoembolisation and Poor Prognosis. J Clin Medicine Res. 2018;10(10): 765-71. https://doi.org/10.14740/jocmr3559w.

\section{Publisher's Note}

Springer Nature remains neutral with regard to jurisdictional claims in published maps and institutional affiliations.

\section{Ready to submit your research? Choose BMC and benefit from}

- fast, convenient online submission

- thorough peer review by experienced researchers in your field

- rapid publication on acceptance

- support for research data, including large and complex data types

- gold Open Access which fosters wider collaboration and increased citations

- maximum visibility for your research: over $100 \mathrm{M}$ website views per year

At BMC, research is always in progress.

Learn more biomedcentral.com/submissions 